\title{
IPTEKS SISTEM INFORMASI PENDATAAN DAN PENAGIHAN PAJAK KENDARAAN BERMOTOR SULUT BERBASIS WEB PADA DINAS PENDAPATAN DAERAH PROVINSI SULAWESI UTARA
}

\author{
Betria S. R. Manopo ${ }^{1}$, Leidi Diana Habindatu ${ }^{2}$, Hendrik Gamaliel ${ }^{3}$ \\ 1,2,3 Jurusan Akuntansi, Fakultas Ekonomi dan Bisnis, Universitas Sam Ratulangi, Jl. Kampus Bahu, Manado, \\ 95115, Indonesia
}

Email : betriamanopo27@gmail.com

\begin{abstract}
The purpose of this study is to find out how to apply the app See Samrat Smart is information systems data collection and billing tax motor vehicle sulut web-based at the office of Dispenda Prov.Sulut. Therefore, See Samrat Smart app that is system data collection and billing tax motor vechile sulut, very useful for the tax to get data shelter taxpayers, which is in arrears tax so that the process of billing tax become more ficilitate the performance of employees are already run the targets are determined. So, with the system performance employees in the office Bapenda prov. Sulut will be more is orderly because directly in control by the leader office with See Samrat Smart app, which is the system of information data and billing vehicle tax motor web-based.

Keywords : Data Collection and Collection Information System, Motor Vehicle Tax
\end{abstract}

\section{PENDAHULUAN}

Dengan Sangat pesatnya perkembangan teknologi, sehingga semua orang khusunya dikalangan mahasiswa sendiri, sangat bergantung pada alat teknologi seperti laptop, Karena sangat dibutuhkan untuk mempermudah membuat tugas-tugas dan Menyimpan data-data sehingga proses perkuliahan menjadi lebih efektif. Oleh sebab itu, Dispenda Provinsi Sulawesi Utara membuat inovasi terbaru Aplikasi See Samrat Smart yaitu Aplikasi Sistem Pendataan dan Penagihan Pajak Kendaraan Bermotor Sulut Berbasis Web, yang terintegrasi dengan sistem database kesamsatan sulut. Tujuan dengan pembuatan aplikasi ini yaitu Menyimpan data-data alamat wajib pajak dan mempermudah petugas pajak untuk mengontrol wajib pajak yang masih menunggak pajak sehingga mempermudah petugas pajak untuk melakukan penagihan pajak. Pajak Kendaran Bermotor (PKB) adalah pajak yang didapatkan dalam suatu daerah yang memeberikan partisipasi untuk menambah pendapatan daerah di provinsi Sulawesi utara. Penagihan pajak kendaraan bermotor dilakukan oleh pemerintah daerah Sulawesi utara sebagai usaha tercapainya pendapatan asli daerah yang tidak memberikan hasil yang memuaskan. Dengan adanya Aplikasi See Samrat Smart yang merupakan Aplikasi Sistem Pendataan Dan Penagihan Pajak ini, akan lebih memperlancar proses penagihan pajak agar tidak ada lagi yang menunggak pajak dan dapat membayar pajak tepat waktu.

\section{TINJAUAN PUSTAKA}

Aplikasi Dan Sistem Informasi. Definisi Aplikasi merupakan subteks perangkat lunak yaitu computer. computer sangat dibutuhkan agar dapat mengerjakan tugas sesuai keinginan pengguna. Oleh karena itu, dalam hal untuk memperlancar pekerjaan dalam dunia computer maka terciptalah sebuah perangkat lunak yan dinamakan aplikasi. Definisi Sistem Informasi merupakan sebuah sistem yang mana terdiri dari teknologi atau alat media yang digunakan, prosedur yang terorganisir, serta sumber daya manusia yang di dalamnya bekerja 
sebagai sebuah kombinasi membentuk sebuah sistem yang terorganisir. Kombinasi antara teknologi dan manusia ini bekerja untuk mendapatkan sebuah informasi yang kemuadian di gunakan untuk mendukung suatu menejemen guna mengambil sebuah kebijakan atau ketetapan.

Penagihan Pajak. Penagihan pajak adalah usaha untuk melunasi hutang pajak dan biaya penagihan pajak dengan cara menegur atau memperingati pada penanggung pajak. Menurut mardiasmo ada 3 unsur dalam penagihan pajak yaitu penanggung pajak, penagihan pajak dan biaya penagihan pajak. Berdasarkan hal tersebut dapat disimpulkan bahwa penagihan pajak adalah tindakan aparatur direktorat jendral pajak yang tidak mematuhi ketentuan undang-undang perpajakan. Penagihan pajak sangat berpengaruh secara simultan maupun parsial. Dalam undang-undang perpajakan terdapat adanya kewajban pajak yang jika tidak dipenuhi maka akan memunculkan tindakan pemaksaan yang terdapat dalam undangundang ini. Tujuan dari penagihan pajak adalah untuk mendapatkan kepastian bahwa penerimaan pajak oleh Negara dapat dipenuhi.

Pajak Kendaraan Bermotor. Pajak kendaraan bermotor (PKB) adalah semua kendaraan yang digunakan dalam transportasi jalan darat, yang digerakka oleh peralatan berupa motor yang berfungsi untuk mengubah sumber daya energi tertentu menjadi tenaga bergerak. Yang menjadi dasar hukum pajak kendaraan bermotor yaitu peraturan daerah nomor 2 tahun 2015 tentang perubahan peraturan daerah nomor 8 tahun 2010 yang mengatur mengenai objek pajak, subjek pajak, wajib pajak, dan segala sesuatu yang berkaitan dengan dunia perpajakan. Objek pajak yaitu transaksi menurut peraturan perpajakan yang biasa disebut sumber pendapatan. Sedangkan subjek pajak adalah istilah yang digunakan dalam undang-undang perpajakan yang menunjuk pada seseorang (pribadi) atau organisasi (kelompok) sesuai peraturan yang berlaku.

\section{METODE DAN PENERAPAN TEKNIK IPTEKS}

\subsection{Metode Penerapan Ipteks}

Dalam prosedur penagihan pajak salah satu cara untuk mempermudah penagihan pajak yaitu dengan menggunakan Aplikasi See Samrat Smart yang merupakan aplikasi Sistem Informasi Pendataan, Penagihan Pajak Kendaraan Bermotor Berbasis web yang dilakukan oleh petugas pajak.

\subsection{Teknik Penerapan Ipteks}

Mekanisme penerapan ipteks dalam aplikasi ini yaitu pada saat petugas pajak melakukan penagihan pajak. Dalam hal ini petugas pajak dapat melihat pajak yang menunggak dalam Aplikasi See Samrat Smart agar membuat pekerjaannya menjadi lebih mudah.

\section{PEMBAHASAN}

\subsection{Gambaran Objek Penerapan Ipteks}

Dalam rangka mempermudah petugas pajak dalam melaksanakan penagihan pajak dan juga mempermudah pimpinan kantor untuk mengawasi pegawai kantor khusunya yang bertugas sebagai petugas pajak, kantor Dinas Pendapatan Daerah mengeluarkan Aplikasi terbaru yaitu Aplikasi See Samrat Smart yang merupakan Aplikasi Sistem Informasi Pendataan, Penagihan Pajak Kendaraan Bermotor Berbasis Web.

\subsection{Pembahasan}

Dinas Pendapatan Daerah Provinsi Sulawesi Utara Membuat inovasi terbaru yaitu Aplikasi See Samrat Smart yang merupakan Sistem Informasi Pendataan dan Penagihan Pajak Kendaraan Bermotor Sulut Yang Berbasis Web. Aplikasi ini dapat memudahkan petugas pajak dalam mengontrol wajib pajak yang masih menunggak pajak dan dapat memudahkan petugas pajak utuk dapat melihat data-data berupa alamat lengkap wajib pajak 
yang belum membayar pajak, sehingga dapat memudahkan petugas pajak dalam melakukan proses penagihan pajak. Aplikasi ini juga dapat membantu memperlancar kegiatan kantor Dinas Pendapatan Daerah Provinsi Sulawesi Utara dalam melakukan proses penagihan pembayaran pajak Kendaraan bermotor karena telah terintegrasi dengan sistem database Samsat Sulut.

Dengan hadirnya pula aplikasi ini dapat memudahkan pimpinan kantor Dinas Pendapatan Daerah Provinsi Sulawesi Utara, untuk mengontrol kinerja pegawai apakah sudah menjalankan tugas dan tanggung jawab yang baik sebagai petugas penagih pajak dan apakah sudah mencapai target yang ditentukan, Tanpa perlu pimpinan kantor turun langsung mengawasi kinerja pegawai khususnya petugas penunggak pajak. Aplikas ini juga dapat di akses memlalui smartphone android, sehingga pimpinan kantor dapat mengontrol kinerja pegawai khusunya petugas penagih pajak dimana saja . Dengan begitu pekerjaan pegawai di kantor akan menjadi lebih tertib karena langsung di kontrol oleh Pimpinan kantor Dinas Pendapatan Daerah Provinsi Sulawesi Utara. Dengan menggunakan Aplikasi See Samrat Smart yang merupakan Sistem Informasi Pendataan dan Penagihan Pajak Kendaraan Bermotor, yang Berbasis Web. Adapun tampilan dari aplikasi See Samrat Smart adalah sbb :

1. Tampilan Saat Login

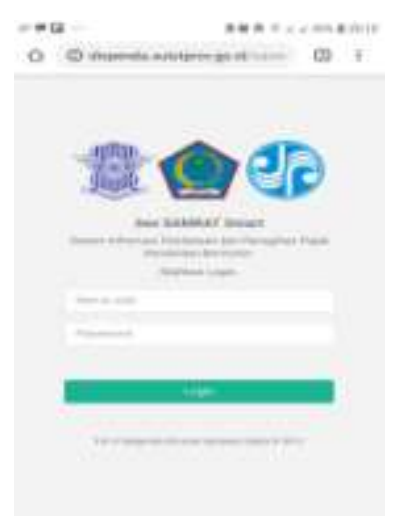

2. Tampilan menu utama

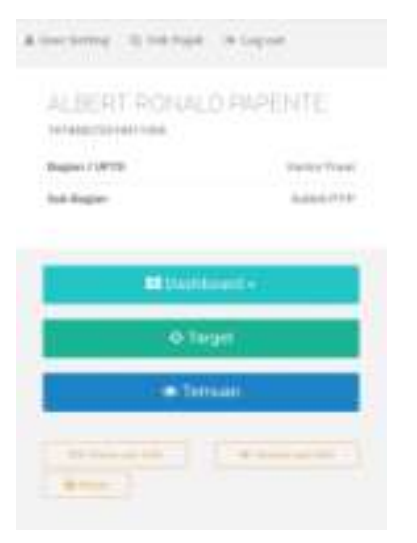


3. Tampilan Informasi Wajib Pajak

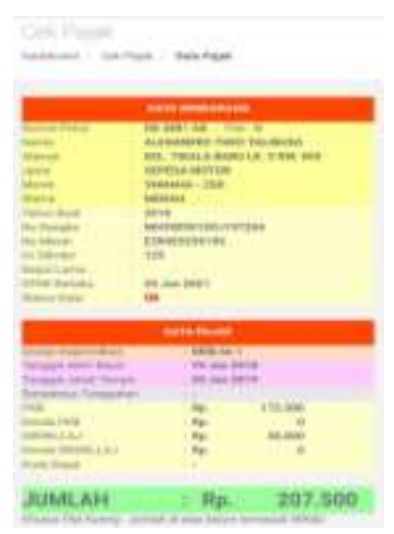

\section{KESIMPULAN DAN SARAN}

\subsection{Kesimpulan}

Aplikasi See Samrat Smart yang merupakan Sistem Informasi Pendataan dan Penagihan Pajak Kendaraan Bermotor Sulut Berbasis Web. Aplikasi ini, Sangat bermanfaat bagi kantor untuk mengontrol orang pribadi atau badan yang masih menunggak pajak, dengan memudahkan petugas pajak untuk menemukan data-data berupa alamat lengkap penunggak pajak agar dapat memudahkan petugas pajak dalam melakukan proses penagihan pajak. Dan aplikasi ini juga dapat memudahkan pimpinan kantor untuk mengontrol semua kinerja pegawai dan menilai kinerja pegawai.

\subsection{Saran}

Penulis berharap aplikasi See Samrat Smart yang merupakan Sistem Informasi Pendataan dan Penagihan Pajak Kendaraan Bermotor Sulut, berbasis web ini dapat terus berkembang dan lebih maju lagi kedepannya. Dengan semakin berkembangnya aplikasi ini, Penulis juga berharap tunggakan pajak akan berkurang bahkan tidak ada lagi wajib pajak yang akan menunggak pajak.

\section{DAFTAR PUSTAKA}

Budiman, A., dan Triono, J. (2016). Sistem Informasi Parkir Kendaraan Bermotor Berbasis Android. Jurnal Ilmiah Ilmu-Ilmu Teknik, 1(1), 42-49.

Dana, M. I. A., Pramuko, A., dan Budiwati, S. D. (2016). Aplikasi Panduan Pembayaran Pajak Kendaraan Berbasis Android, 2(1), 122-131.

Febrianti. (2011). Analisis Sistem Pengendalian Pemungutan Pajak Kendaraan Bermotor Dalam Peningkatan PAD Pada Dispenda Kota Singkawang. Jurnal Eksos, 7(2), 165185.

Fitriani, Y., dan Pakpahan, R. (2018). Aplikasi Sistem Informasi Pengelolaan Arsip Pada Unit Pelayanan Pajak Dan Retribusi Daerah Palmerah Jakarta. Jurnal Komputer Dan Informatika Akademi Bina Saran Informatika, XX (2), 51-56.

Kurniasari, P., dan Kesuma, A. (2016). Efektivitas Penagihan Pajak Dengan Surat Teguran Dan Surat Paksa Terhadap Penerimaan Pajak Pada Kantor Pelayanan Pajak (KPP) Pratama Di Balikpapan. Jurnal Ekonomi Dan Keuangan, 13(1), 21-31.

Lydiana. (2018). Pengaruh Kesadaran Wajib Pajak, Pengetahuan Pajak, Dan Sanksi Pajak Terhadap Kepatuhan Wajib Pajak Orang Pribadi Di KPP Pratama Surabaya Gubeng. Jurnal Ilmiah Mahasiswa Universitas Surabaya, 7(1), 125-133. 
Mohammad, I., Saerang, D. P. E., dan Pangerapan, S. (2017). Pengaruh Pemeriksaan Dan Penagihan Pajak Terhadap Penerimaan Pajak Pada Kantor Pelayanan Pajak Pratama Manado. Jurnal Riset Akuntansi Going Concern, 12(2), 938-949

Mokoginta, N. C. (2015). Analisis Efektivitas Prosedur Pemungutan Pajak Kendaraan Bermotor Dan Bea Balik Nama Kendaraan Bermotor Dalam Peningkatan PAD Provinsi Sulawesi Utara. Jurnal EMBA : Jurnal Riset Ekonomi, Manajemen, Bisnis Dan Akuntansi, 3(1), 685-694.

Mulyawan, A., dan Dini, N. (2016). Aplikasi Pembayaran Pajak Kendaraan Bermotor Online Berbasis Web (Studi Kasus Di Samsat Soreang Kab. Bandung). Jurnal Computech Dan Bisnis, 10(1), 30-39.

Palupi, D.Y., dan Herianti, E. (2017). Pengaruh Pemeriksaan Dan Penagihan Pajak Terhadap Kepatuhan Wajib Pajak Dengan Informasi Tren Media Sebagai Variabel Moderating (Studi Kasus KPP Pratama Jakarta Kebayoran Baru Tiga). Jurnal Infestasi, 13(1), 285-296.

Rompis, N. E., Ilat, V. dan Wangkar, A. (2015). Analisis Kontribusi Kendaraan Bermotor Terhadap Pendapatan Asli Daerah Provinsi Sulawesi Utara (Studi Kasus Pada Samsat Airmadidi). Jurnal Berkala Ilmiah, 15(3), 51-62.

Rosyidi, F. (2014). Pengaruh Penagihan Pajak Dengan Surat Teguran Dan Surat Paksa Terhadap Kepatuhan Wajib Pajak Dilingkungan Kanwil DJP Jawa Tengah I Dan Jawa Tengah II. Jurnal Akuntansi Indonesia, 3(1), 47-58. 